\title{
Robust Market Launch Planning for a Multi- Echelon Pharmaceutical Supply Chain
}

\author{
Hansen, Klaus Reinholdt Nyhuus; Grunow, Martin; Gani, Rafiqul
}

Published in:

21st European Symposium on Computer Aided Process Engineering

Link to article, DOI:

10.1016/B978-0-444-53711-9.50187-5

Publication date:

2011

Link back to DTU Orbit

Citation (APA):

Hansen, K. R. N., Grunow, M., \& Gani, R. (2011). Robust Market Launch Planning for a Multi- Echelon Pharmaceutical Supply Chain. In 21st European Symposium on Computer Aided Process Engineering (Vol. 1, pp. 935-939). Elsevier. Computer Aided Chemical Engineering No. 29 https://doi.org/10.1016/B978-0-44453711-9.50187-5

\section{General rights}

Copyright and moral rights for the publications made accessible in the public portal are retained by the authors and/or other copyright owners and it is a condition of accessing publications that users recognise and abide by the legal requirements associated with these rights.

- Users may download and print one copy of any publication from the public portal for the purpose of private study or research.

- You may not further distribute the material or use it for any profit-making activity or commercial gain

- You may freely distribute the URL identifying the publication in the public portal 


\title{
Robust Market Launch Planning for a Multi- Echelon Pharmaceutical Supply Chain
}

\author{
Klaus Reinholdt Nyhuus Hansen ${ }^{a}$, Martin Grunow ${ }^{b}$, Rafiqul Gani ${ }^{a}$ \\ ${ }^{a}$ Technical University of Denmark, Kgs. Lyngby 2800, Denmark \\ ${ }^{b}$ Technische Universität München, München 80804, Germany
}

\begin{abstract}
It is well known, that the pharmaceutical industry is struggling with increasing cost and length of R\&D projects. Earnings of a drug drop drastically after patent expiration. Thus, the industry spends much effort on reducing Time-to-Market. In the literature, little attention is given to drug launching activities after the drug has been approved. In this paper, we present a recourse-based stochastic model, which allows for time phasing the market entries to balance the fluctuating demand with the fixed and periodic production of the active pharmaceutical ingredient. The two major risk elements during launch are forecasting inaccuracy and the risk of a required label change from local regulatory authorities. Robust solutions are found by implementing the Robust Optimization framework.
\end{abstract}

Keywords: Market Launch Planning, Multi-Echelon Pharmaceutical Supply Chain, recourse-based stochastic programming, Robustness Optimization,

\section{Introduction}

The process of launching a new drug is receiving a lot of attention from the pharmaceutical companies as they are under pressure to launch new drugs faster to counter the increasing $R \& D$ cost. To help solve this issue three distinct planning problems related to introduction of new products have been identified in [1]; planning (1) the portfolio of investigational new drugs, (2) the capacity level which will satisfy future requirements, and (3) the production of the drug. The first two planning problems include the uncertainty of obtaining an approval for the drug. Here attention is given to the two main activities after the approval is obtained; the preparation of the supply chain for the launch and the negotiations to determine sales price and subsidies with local authorities. First, supply chain preparations are necessary due to the fixed and periodic supply of the active pharmaceutical ingredient, which is insufficient to supply the initial 
surge for the drug required to fill the entire downstream supply chain. Secondly, it is required that negotiations are carried out with local authorities before entering a market, since packaging material has to be approved and subsidies and sales prices negotiated.

Two central risks influence operations. First, the demand forecast uncertainty for a new drug is very large. The drug manufacturer has to determine a balance between investing in inventory and the risk of supply shortage, which is difficult to overcome due to the limited flexibility of the production processes. Secondly, the regulatory authorities can demand changes in the packaging material. As a result, any finished i.e. packaged products on inventory have to be scrapped. It cannot be repackaged. A pharmaceutical company has to decide on, whether to place the stock further upstream; see the divergent supply chain in figure 1 (a). That would reduce the scrapping risk but increase the Time-toMarket [TTM]. Alternatively, the company can focus on short TTM by packaging the product prior to the negotiations; aptly called risk packaging because of the risk for scrapping the packaged products.

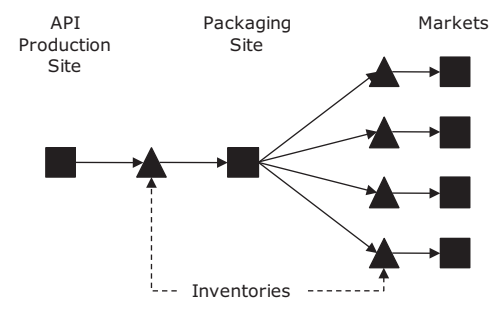

(a)

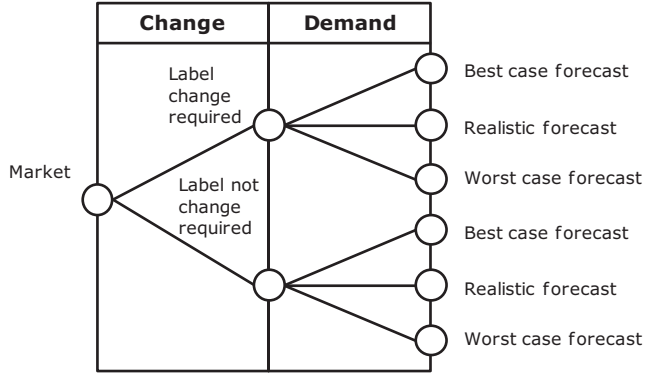

(b)

Figure 1: (a) The divergent supply chain and (b) the scenario tree structure for each market.

In our approach we handle both risk elements by use of stochastic program with recourse for the six scenarios for each market seen in figure 1 (b). . In programming with recourse, variables are divided into design variables, which are independent of the uncertain parameter and control variables, which allow for corrective measures as the uncertain data becomes known. Since production must be planned ahead, flow variables before and at the packaging site are design variables; see figure 1 (a). The remaining downstream variables are control variables. It is assumed that both uncertainties are revealed simultaneously. A good review of the recourse terminology is given in [2].

Solving a program with recourse gives the best expected solution, but may lead to solutions that are highly vulnerable to scenarios with a large downside. Managers in the pharmaceutical industry are often risk averse and prefer stable solution despite reduced expected profit. To get solutions that are less sensitive to variations in the uncertain parameter, [3] developed a Robust Optimization framework. By penalizing the objective function with the variance of the 
Robust Market Launch Planning for a Multi-Echelon Pharmaceutical Supply Chain

solution, solutions are found where the objective function value stays close to the expected solution despite variations in the uncertain parameter. In [4] the framework is applied to a planning model of a network of chemical processes.

\section{Model Formulation}

Due to space limitation we only present key equations from the MILP model. The sets used are $m \in M$ for markets, $t \in T$ for time and $s \in S$ for scenarios.

\subsection{Market Access and Market Launch Constraints}

Equations $1-3$ below are used for time phasing market launches, $l_{m t}$, and starting the reimbursement negotiation, $c_{m t}$. The drug can be launched only once in each market according to Eq. 1. Eq. 2 forces reimbursement negotiations with length $N_{m}$ to be completed before a launch. Eq. 3 limits the number of negotiations carried out at any given time to reflect resource limitation on e.g. personnel to conduct the negotiations for the company.

$$
\begin{array}{ll}
\sum_{t=1}^{T} l_{m t} \leq 1 & \forall m \in M \\
\sum_{t^{\prime}=1}^{t-N_{m}} c_{m t^{\prime}} \geq l_{m t} & \forall m \in M, t \in T \\
c_{m t}+\sum_{m^{\prime} \in M \backslash\{m\}} \sum_{t^{\prime}=t-N_{m}+1}^{t} c_{m^{\prime} t^{\prime}} \leq N C & \forall m \in M, t \in T
\end{array}
$$

\subsection{Supply Chain Flow Constraints}

The inventory balance in Eq. 4 is the only supply chain flow constraints shown here. Here the added scrap variable, $s c_{m t s}$, is needed for the scenarios in which a label change is required, forcing the company to dispose of the finished product inventory. $r_{m t s}$ is the amount of products required given the demand. im $m$ ts and $p m_{m t}$ are the market specific amounts of inventory and packaged drug respectively, as the drug becomes market specific in the packaging stage.

$$
i m_{m, t-1, s}-s c_{m t s}+p m_{m t}=r_{m t s}+i m_{m t s} \quad \forall m \in M, t \in T, s \in S
$$

\subsection{Scrap Constraint}

The scrap variable from Eq. 4 is set through Eq. 5. The variable is the same as the inventory on hand after the previous period, only if the reimbursement negotiations are just concluded in $t$ i.e. started $N_{m}$ periods before and the scenario prescribes a label change via $I P_{m s}$. Here $K$ is a large number. 


$$
s c_{m t s} \geq i m_{m t-1 s}-K \cdot\left(1-c_{m t-N_{m}} \cdot I P_{m s}\right) \quad \forall m \in M, t \in T, s \in S
$$

\subsection{Objective Function}

The profit as given in Eq. 6 is to be maximized, where $\varepsilon_{m s}\left(l_{m t}, i m_{m t s}, s c_{m t s}\right)$ is the cash flow as a function of (i) the revenue of sales given $l_{m t}$, (ii) the holding cost given $i m_{m t s}$ plus the upstream inventory and (iii) the scrapping cost given $s c_{m t s}$. $L_{m s}$ denotes the probability of each scenario for each market.

$$
\max \sum_{m=1}^{M} \sum_{s=1}^{S} L_{m s} \cdot \varepsilon_{m s}\left(l_{m t}, i m_{m t s}, s c_{m t s}\right)
$$

All continuous variables are positive and inventory variables and flow variables describing packaged quantities have limited capacity. The design variables presented here are $\left(c_{m t}, l_{m t}, p m_{m t}\right)$ and the control variables are $\left(i m_{m t s}, s c_{m t s}, r_{m t s}\right)$.

\subsection{Inclusion of Robust Optimization}

The model presented above is a typical MILP model with recourse. This solution is exposed to scenarios with potential low profit or even loss. To reflect risk aversion, the Robust Optimization framework from [3] is implemented. Here Eq. (7) is added to Eq. (6), since profit should be maximized:

$-\lambda \cdot \sum_{m=1}^{M} \sum_{s=1}^{S} L_{m s} \cdot\left(\left(\varepsilon_{m s}-\sum_{s^{\prime}=1}^{S} L_{m s^{\prime}} \cdot \varepsilon_{m s^{\prime}}\right)+2 \cdot \theta_{m s}\right)$

$\lambda$ is a weight, which can be set freely and is a measure of the risk aversion. Higher $\lambda$ equals higher penalty in the objective function and reflects higher risk aversion. Eq. 7 penalizes the effect of radical scenarios with the difference between the scenario and the expected solution. $\theta_{m s}$ used in [5] ensures that the expression is positive, where $\theta_{m s}$ is found through Eq. 8 .

$$
\theta_{m s} \geq \sum_{s^{\prime}=1}^{S} L_{m s^{\prime}} \cdot \varepsilon_{m s^{\prime}}-\varepsilon_{m s} \quad \forall m \in M, s \in S
$$

Presentations of the Restricted Recourse framework and model robustness have been omitted due to the lack of space. Please refer to [4] and [3], respectively.

\section{Illustrative Example}

Data has been created to reflect a realistic case study, which includes 10 markets over a 30 period time horizon. In figure 2 markets covered for both the Market Launch Planning model [MLP] i.e. including equations 1 to 6 and the Robust Market Launch Planning model [RMLP] i.e. including equations 1 to 8 can be seen. Here delays are gaps between completion of negotiations and market launch. The risk aversion weight, $\lambda$, is set to 1 . As the approval of the 
Robust Market Launch Planning for a Multi-Echelon Pharmaceutical Supply Chain

drug is given in period 12, negotiation cannot start before. After period 17, no new markets are entered for either model as ramp up of capacity follows the increase in demand.

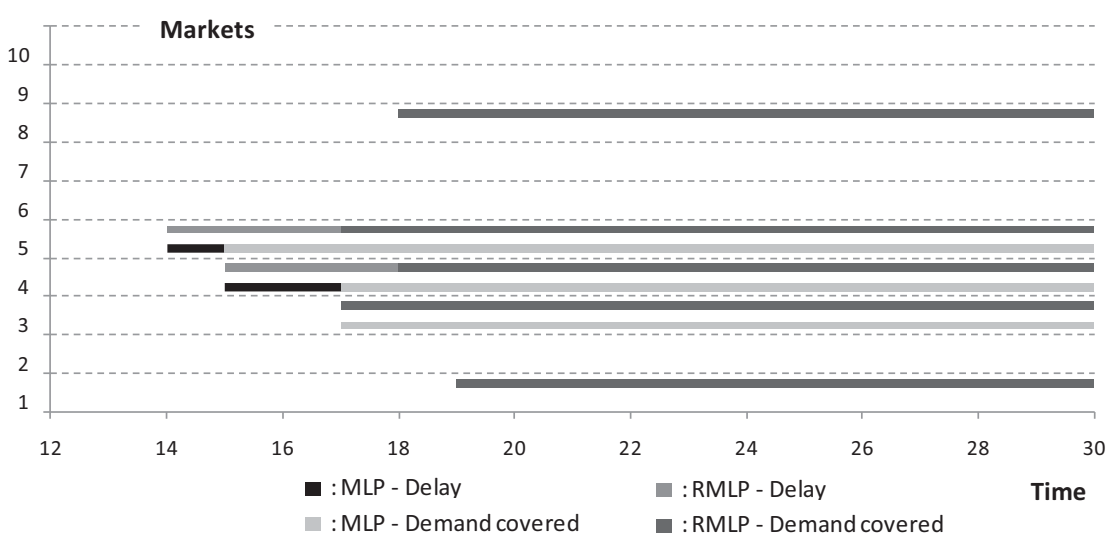

Figure 2: Illustration of selected markets and delay between launch and negotiation completion.

As can be seen, the main difference in the solutions is that RMLP launches the drug in more and smaller markets and awaits the outcome of the negotiations in the larger markets 4 and 5. The profit for both solutions is almost the same, while revenue is reduced less than $1 \%$ for RMLP compared to MLP. In the RMLP solution, the expected scrap is reduced by $33 \%$, though holding cost rises $13 \%$ compared to MLP. The percentage of total inventory held at the upstream stocking point only increases less than $1 \%$ for the RMLP, since more inventory of packaged drug is held to supply more markets. In the RMLP model the variance and maximum deviation are reduced $31 \%$ and $28 \%$ respectively compared to the MLP model. Computation time is 26 seconds and 39 seconds for the MLP and the RMLP, respectively.

\section{Conclusion and Further Work}

We presented a modeling approach for planning market launches of new pharmaceutical products, which included a robust opimization framework. The model was tested for a case to illustrate its effectiveness. Future work will focus on linking the modeling approach to capacity planning and production planning.

\section{References}

[1] N Shah. Computers and Chemical Engineering 28 (2004) 929.

[2] NV Sahinidis. Computers \& Chemical Engineering 28 (2004) 971.

[3] JM Mulvey, RJ Vanderbei, SA Zenios. Operations research 43 (1995) 264.

[4] S Ahmed, NV Sahinidis. Industrial \& Engineering Chemistry Research 37 (1998) 1883.

[5] CS Yu, HL Li. International Journal of Production Economics 64 (2000) 385. 